\title{
Surgical judgement in assessing the need for cavity shaves during breast conserving surgery
}

\author{
Sarah Elizabeth Clark, Simon George Twyman Smith \\ The Breast Unit, Broomfield Hospital, Broomfield, Chelmsford, Essex, U.K. \\ Correspondence: Sarah Elizabeth Clark. Address: The Breast Unit, Broomfield Hospital, Court Road, Broomfield, \\ Chelmsford, Essex, CM1 7ET, U. K. Email: sarahclark74@hotmail.com
}

Received: November 7, 2013

Accepted: December 5, 2013

Online Published: December 8, 2013

DOI : $10.5430 /$ jst.v3n6p38

URL: http://dx.doi.org/10.5430/jst.v3n6p38

\section{Abstract}

Background: The majority of patients with breast cancer in the UK undergo breast conserving surgery (BCS). Breast Conserving Surgery followed by post-operative Radiotherapy has the same 10 year survival rates as mastectomy but a higher incidence of local recurrence. One of the factors associated with local recurrence is tumour cell presence at the specimen resection margin. In order to avoid this some surgeons take extra pieces of tissue from the cavity walls after removal of the main specimen which are known as cavity shaves (CS). However, there is no consensus on adequate radial margin size or the use of cavity shaves. In this study we have analysed the outcomes of patients undergoing Breast Conserving Surgery and the use of cavity shaves in our unit.

Methods: All patients who underwent BCS at our unit over a three year period were included in the study. Data collected from the Pathology report included specimen weight, tumour size, presence of tumour at radial margins and whether cavity shaves had been taken. An assessment was then made on whether the cavity shave correlating to the site of tumour at the radial margin had been taken correctly. The patients' outcome in terms of further surgery was also assessed.

Results: 323 cases were included in the analysis and of these 138 had one or more CS taken at time of BCS. 88 of these 138 had clear radial margins and 50 had involved radial margins. Surgeons correctly removed the corresponding CS to involved margin in $44.5 \%$ of cases.

Conclusions: Breast surgeons are poor at using intra-operative specimen X-rays or palpation of the specimen in assessing whether tumour is present at the radial margin of a breast excision specimen during breast conserving surgery. The use of cavity shaves leads to unnecessary excision of breast tissue.

\section{Key words}

Breast cancer, Breast conserving surgery, Radial margins, Cavity shaves, Surgical judgment

\section{I ntroduction}

Most patients with breast cancer in the UK are surgically treated with breast conserving surgery (BCS) ${ }^{[1]}$. In combination with adjuvant radiotherapy, BCS achieves near equal survival rates to mastectomy, however the 10 year local recurrence rate from BCS is higher than mastectomy at between 2 and $23 \%{ }^{[2-7]}$. Factors associated with local recurrence include positive excision margins, younger patient age, tumour size and presence of in situ disease ${ }^{[8-11]}$. Removal of breast tissue 
containing tumour during breast conserving surgery is known as a wide local excision (WLE). The tumour should have a tumour-free rim of tissue surrounding it. This rim of tissue is known as the margin. In order to ensure clear margins some surgeons take extra pieces of tissue by shaving the walls of the cavity from which the WLE specimen has been removed which are termed cavity shaves (CS). These are illustrated in Figure 1.

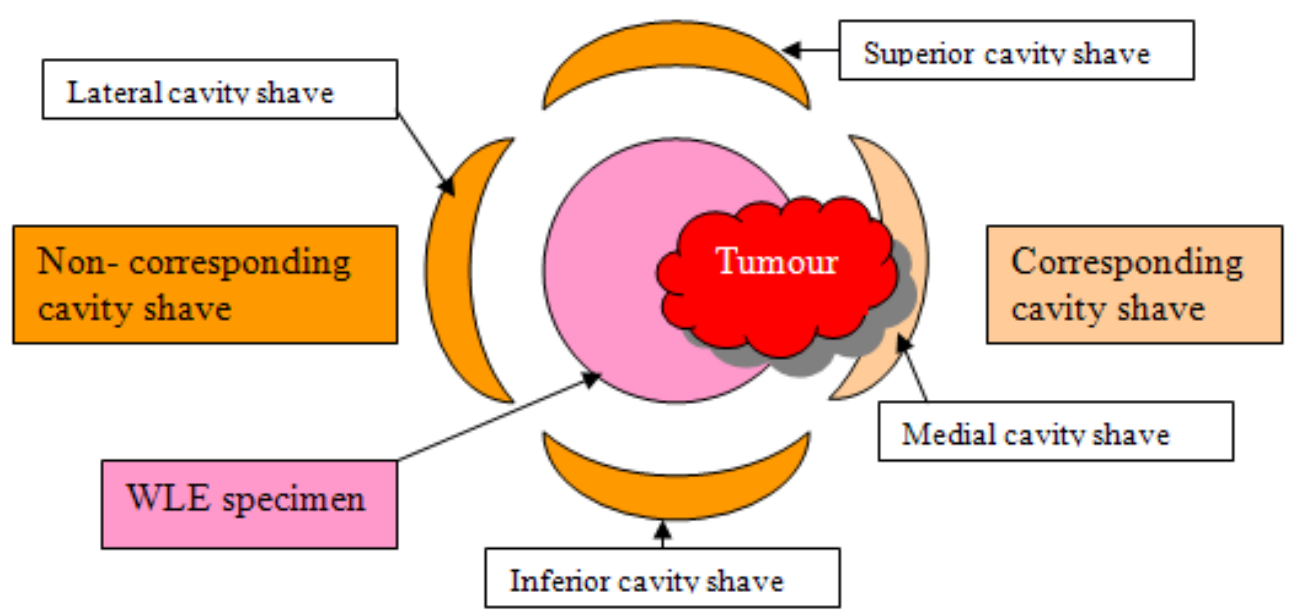

Figure 1. Representation of a Wide Local Excision (WLE) specimen with corresponding and non-corresponding cavity shaves

Currently there is no consensus on the adequate margin for excision for invasive breast cancer. In the UK the Association of Breast Surgery, National Institute for Clinical Excellence (NICE) and National Health Service Breast Screening Programme (NHSBSP) guidelines all allow Breast units to decide their own margin size as part of a multidisciplinary team. There is also no national guidance on the use of cavity shaves and no published data on surgeons' current use of cavity shaves. Some surgeons routinely take cavity shaves from all radial margins whilst others only take them if they have concerns regarding margin involvement at the time of surgery, guided by physical or intra-operative radiological assessment of the specimen. In this study we have analysed our use of cavity shaves after wide local excision and tried to gauge how good surgeons are at assessing margin involvement at the time of surgery.

\section{Methods}

A retrospective analysis was undertaken of all patients who underwent wide local excision of a primary breast cancer at Broomfield hospital between 01/01/2009 and 31/12/2011. Screen-detected and symptomatic patients were included; impalpable lesions were localised using image-guided wire placement pre-operatively. Patients who had received neo-adjuvant chemotherapy, and those who underwent therapeutic mammoplasty were excluded. Deep and superficial margin involvement did not result in further surgery, as all BCS specimens were full thickness from skin to pectoral fascia, though involvement of these margins may have influenced adjuvant treatment decisions. In this study we analysed the radial margins and whether cavity shaves (CS) were taken during the first operation. Clear margins were regarded as $\geq 2 \mathrm{~mm}$. Involved margins were defined as $<2 \mathrm{~mm}$ or had tumour at the cut excision surface. Surgery was performed by four Consultant Breast Surgeons or by a trainee under their direct supervision. There was no unit policy on taking CS during the study period. One Surgeon took four CS in most, though not all cases. The other three Surgeons took CS after examining the intra-operative specimen radiograph, or if tumour was palpable close to a margin.

Patients were identified from the Breast Unit database. Data were collected from the Hospitals Electronic Pathology results system and patients case notes. The specimen weight was taken from the histopathology result and is therefore the weight of the specimen after it had been fixed in formalin. The overall size of the tumour included both invasive and 
non-invasive elements in continuity and the grade and histological type of the tumour was recorded. Details of any CS were taken and then analysed to see if the corresponding CS to involved margin could be correlated. The corresponding CS was the one adjacent to the margin containing tumour as illustrated in Figure 1. Patient outcomes were then evaluated.

Statistical analysis was performed using the chi-squared test.

Table 1. Specimen and tumour characteristics

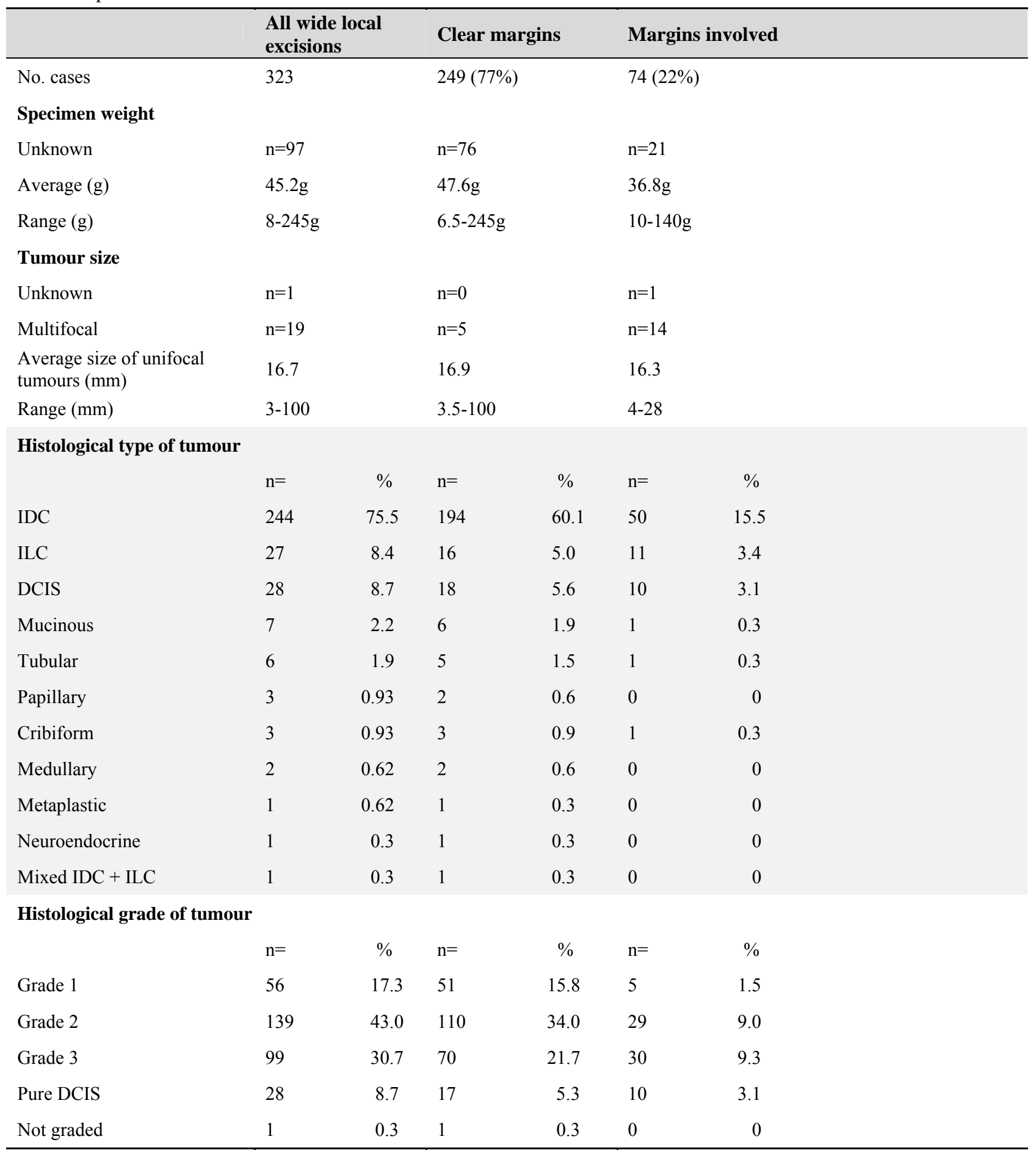

IDC= Invasive Ductal Carcinoma; ILC= Invasive Lobular Carcinoma; DCIS= Ductal Carcinoma in-situ 


\section{Results}

There were 354 wide local excisions (WLE) performed between 01/01/2009 and 31/12/2011 and of these 31 were excluded from the analysis. This was because one case had simultaneous cores during the operation which were found to contain DCIS, in two of the cases the results could not be found on the hospitals electronic pathology system and 28 of the cases had undergone neo-adjuvant chemotherapy. Therefore the number of cases analysed was 323.

The weight of the resection specimen was recorded in 225 of the 323 cases. The average weight was $45.2 \mathrm{~g}$ (range 8-245g). Tumour size was taken as the total size of continuous invasive +/- non-invasive disease. 19 of the 323 cases were multifocal tumours and therefore not involved in the size analysis. In one case the tumours size was not recorded. The 303 tumours that were unifocal had an average size of $16.7 \mathrm{~mm}$ (range $3-100 \mathrm{~mm}$ ). This data and the histological grade and type of the tumours can be seen in Table 1 .

249 (77.1\%) of the WLE specimens had clear margins. The average weight of these specimens was $47.6 \mathrm{~g}$ (range $6.5-245 \mathrm{~g}$ ) and the average tumour size was $16.9 \mathrm{~mm}$ (range 3-100mm) in unifocal cases. Five of the 19 multifocal cases had clear radial margins ( $1.5 \%$ of the total cases). 74 cases $(22.9 \%)$ had one or more involved margins. The average weight of specimens with involved margins was $36.8 \mathrm{~g}$ (range $10-140 \mathrm{~g}$ ) and the average tumour size was $16.3 \mathrm{~mm}$ (range 4-28mm). 14 of the 19 multifocal tumours (5.1\% of the total cases) had involved margins. There was no difference between histological type and grade between cases with clear or involved margins. This data is also shown in table 1.

\subsection{Cavity shaves}

138 cases had one or more CS taken during the first operation. One CS was taken in 51 cases, two CS were taken in 44 cases, three CS were taken in 19 cases and four CS were taken in 24 cases. Therefore a total of 292 CS were taken in 138 patients. Of the 138 cases 88 had clear radial margins in the main specimen. There were $192 \mathrm{CS}$ taken in these 88 patients. In 17 of the 88 cases where the radial margins were clear and CS had been taken, tumour was found in the CS. The outcomes of these patients are shown schematically in Figure 2.

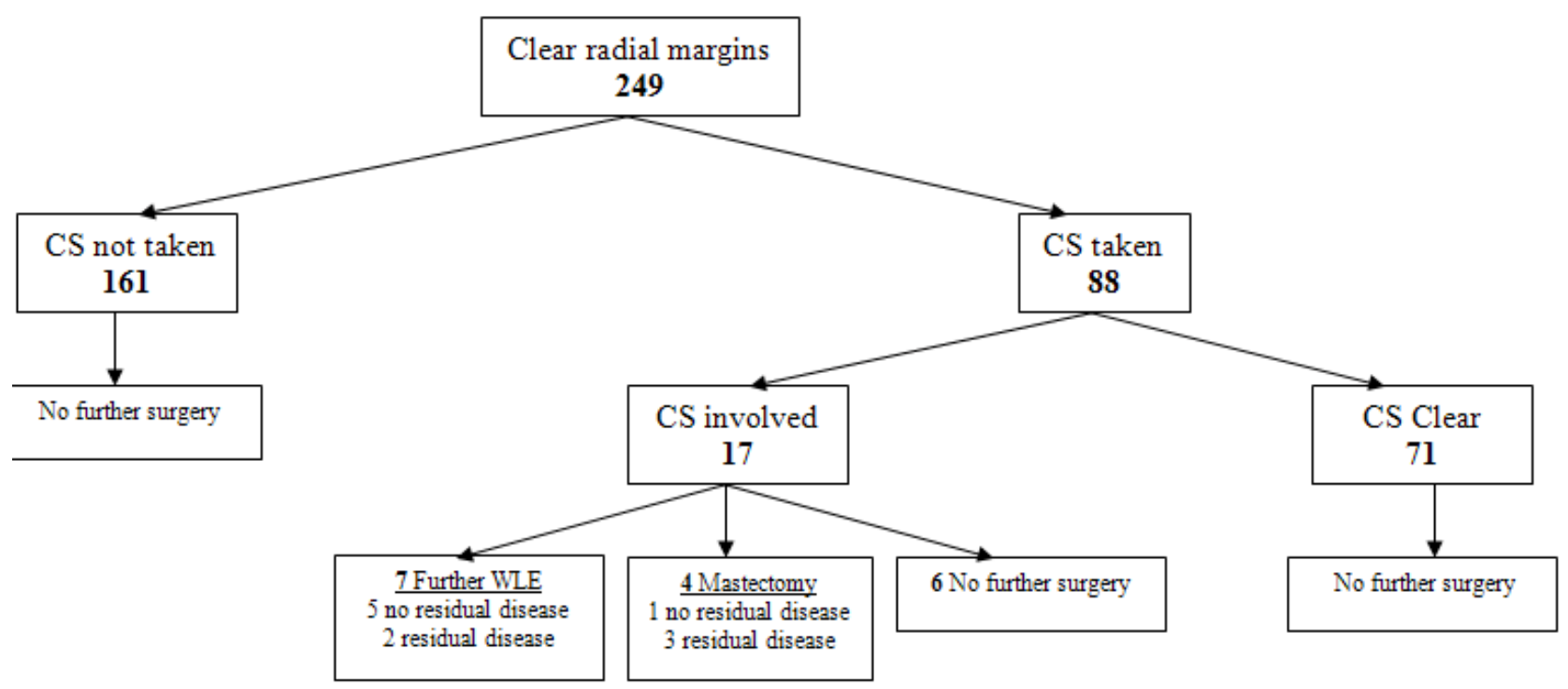

Figure 2. Outcomes of cases with clear radial margins showing whether cavity shaves (CS) have been taken

The 50 cases that had one or more involved margin and CS taken were analysed in more detail to identify if the CS corresponding to the involved margin was taken. Of these 50 cases, 33 had one margin involved, 14 had two margins involved and three cases had three margins involved. There were no cases that had all four radial margins involved. Overall for the 50 cases there were 71 involved margins. The majority of these cases had either one or two CS taken (18 
and 14 cases respectively). In eight cases three CS were taken and all four CS were taken in 10 cases. This gave a total of $110 \mathrm{CS}$ taken for 70 positive margins in 50 cases. Of the $110 \mathrm{CS}$ shaves taken 49 (44.5\%) corresponded to an involved margin in the main specimen and $61(55.5 \%)$ did not. Table 2 shows the number of cavity shaves taken in cases with involved radial margins, the number of margins involved and whether the corresponding margins were taken.

Table 2. Analysis of cavity shaves taken in cases with involved radial margins

\begin{tabular}{lllll}
\hline $\begin{array}{l}\text { Number of } \\
\text { cavity shaves } \\
\text { taken }\end{array}$ & $\begin{array}{l}\text { Number of cases } \\
\text { with involved } \\
\text { margins }\end{array}$ & $\begin{array}{l}\text { Total number of } \\
\text { margins involved }\end{array}$ & $\begin{array}{l}\text { Number of cavity shaves } \\
\text { corresponding to } \\
\text { involved margin taken }\end{array}$ & $\begin{array}{l}\text { Number of cavity shaves } \\
\text { not corresponding to } \\
\text { involved margin taken }\end{array}$ \\
\hline 1 & 18 & 24 & 13 & 5 \\
2 & 14 & 18 & 11 & 17 \\
3 & 8 & 13 & 10 & 14 \\
4 & 10 & 15 & 15 & 25 \\
\hline
\end{tabular}

i. e. In 18 cases that had one cavity shave taken there were 24 involved margins. The correct cavity shave was taken for 13 of the margins, the incorrect cavity shave was taken for five margins and six margins did not have a corresponding cavity shave taken.

Overall in the 50 cases with involved radial margins 49 corresponding CS were taken and 61 non-corresponding CS were taken out of 70 involved margins. $182 \mathrm{CS}$ were taken in 88 patients with clear margins although further tumour was found in 17 of these CS. 11 of the non-corresponding CS also contained tumour. Therefore, a total of 215 unnecessary CS were taken.

\subsection{Outcomes}

\subsubsection{Radial margins involved but no cavity shave taken}

There were 24 cases that had one or more radial margins involved but did not have cavity shaves taken. 23 of these went on to have further surgery; 15 had further WLE, five of whom had residual disease and 10 did not. Eight patients underwent mastectomy, of whom three had residual disease and five did not. This is illustrated in Figure 3.

\subsubsection{Radial margins involved and CS taken}

In 27 of the 50 cases that had involved margins and CS taken, the corresponding CS had been taken and was either clear or resulted in a new margin $>2 \mathrm{~mm}$ so no further surgery was required. In one case, although the CS corresponding to the involved margin was taken and clear, tumour was found in a non-corresponding CS and so the patient underwent mastectomy.

Seven of the cases with involved margins that had corresponding CS shaves taken had tumour in the CS which reached the new margin. Three of these proceeded to further excision and three to mastectomy. One did not undergo further surgery.

Not all corresponding CS were taken in nine cases with involved margins; four of these had a further excision and two had mastectomies. In six cases with involved margins non-corresponding margins were taken; three of these underwent further excision, one had a mastectomy and one had a therapeutic mammoplasty. These outcomes are represented schematically in figure 3.

Overall, of the 74 cases with involved margins, 27 had clear CS negating the need for further surgery, 24 did not have CS and so required further surgery (of which 23 did have) and 23 had involved or non-corresponding CS requiring further surgery (of which $18 \mathrm{did}$ ). 


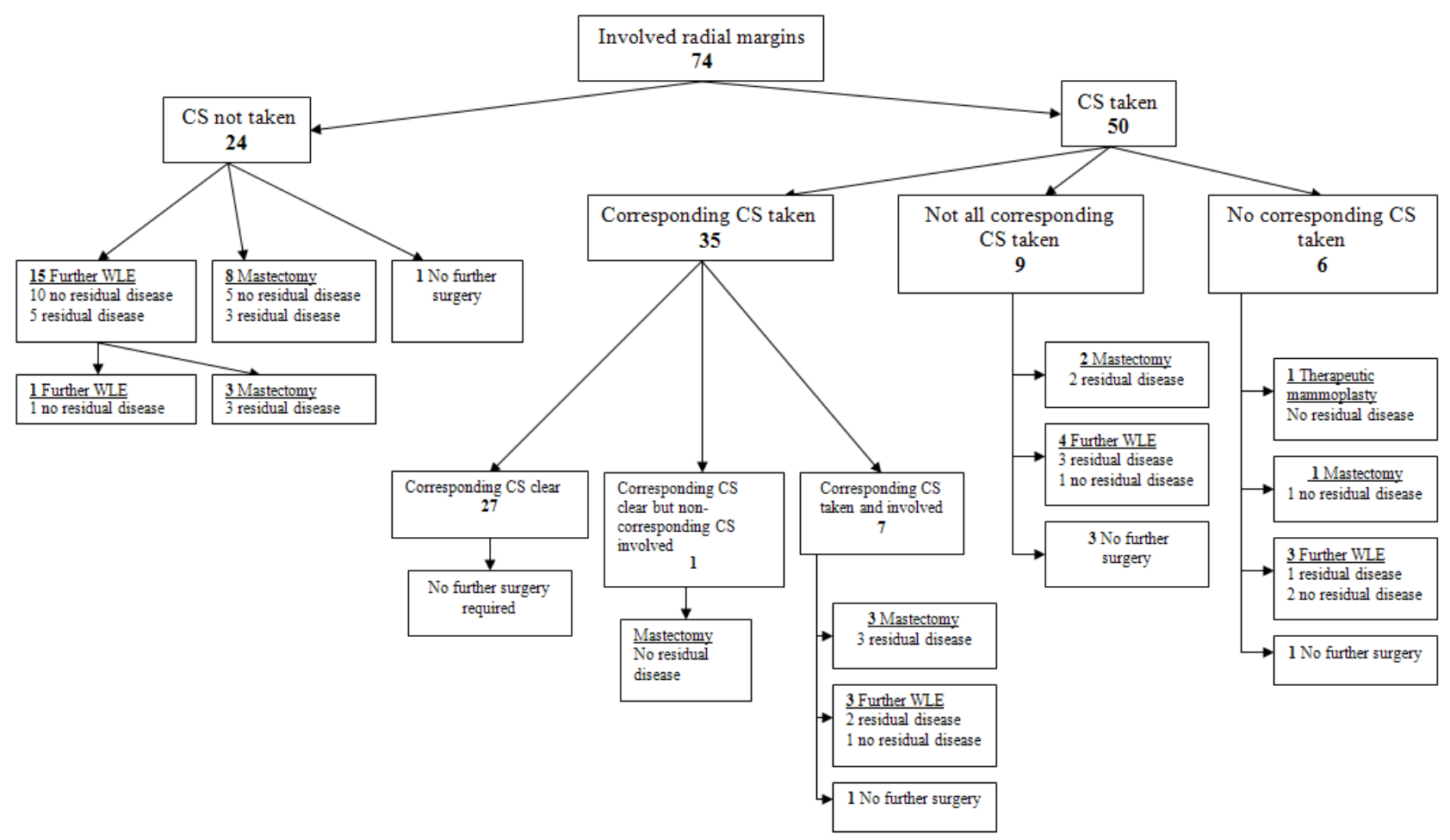

Figure 3. Outcomes of cases with involved radial margins showing whether cavity shaves (CS) have been taken

\section{Discussion}

The 10 year local recurrence rate after wide local excision and radiotherapy is $2.5-28 \%{ }^{[10,12-14]}$. Factors that have been associated with an increased rate of recurrence after WLE include younger age at diagnosis, tumour size, tumour type (Invasive Lobular Carcinoma), extensive in situ disease, palpability, nodal status and positive excision margins ${ }^{[2,8-11]}$. The aim of wide local excision is always to achieve clear surgical margins at the first operation which is why some surgeons choose to take cavity shaves. Re-operation rates within three months of WLE in the UK in 2008 were $20 \%{ }^{[15]}$. In this study our re-operation rate was $12.4 \%$ as $8 \%$ of patients who required re-operation due to involved margins either chose not to have further surgery, it was deemed unnecessary because there was no further tissue to take, or were unfit to undergo a second operation. Re-excision is associated with increased risk of poor healing and poor cosmesis ${ }^{[16]}$ as well as causing psychological distress to the patient. Re-excisions may also be a predictor of local recurrence. Although this was not shown in a retrospective review of 1430 WLE by Aziz et al ${ }^{[13]}$, Menes et al ${ }^{[17]}$ found that the need for two or more re-excisions increased the local recurrence rate to $13.4 \%$ compared to $5.6 \%$ after one re-excision and $3.5 \%$ after no re-excisions in a retrospective analysis of 459 WLE cases.

In this study specimens with involved margins were on average smaller by weight than those with clear margins (36.8g versus $47.6 \mathrm{~g}$ ), although this was not statistically significant ( $p=0.2)$. Tumour size was the same in the two groups $(p=0.9)$. Specimens with involved margins were more likely to contain multifocal tumours than those with clear margins $(p=0.03)$.

Cavity shaves were not routinely taken after WLE and although one surgeon tended to take all four CS he did not always do so. The other surgeons used their judgement after reviewing the specimen radiograph and palpating the resected specimen. To assess surgical judgement in taking CS we looked at the 114 cases that had one, two or three CS taken. $72.6 \%$ of these had clear margins and therefore had unnecessary CS taken. In the 40 cases with involved margins the correct CS was taken in $85 \%$. This would indicate that surgeons are only good at assessing which margin is involved when it is truly involved; however, they are more likely to overestimate margin involvement and take unnecessary CS. 
17 patients who had clear radial margins were found to have tumour in the CS. These patients would have been left with residual disease in the breast if CS had not been taken. 24 patients had involved radial margins but did not have CS taken. 8 of these had residual disease at second operation. It is unknown if taking CS would have prevented them from needing a second operation. Nine patients did not have all the corresponding CS taken and only one of these did not have residual disease at the second operation. Again, it is unknown if routinely taking all four CS could have prevented these patients from requiring a second operation. Six patients had non-corresponding CS taken, four of whom had no residual disease at second operation. These patients may have avoided a second operation if four CS had been taken. Therefore CS identified 17 patients who would have had tumour left behind as radial margins were clear and the routine use of four CS taken during WLE would have had the potential to avoid further surgery in 25 cases.

In our study the use of CS negated the requirement for re-excision in 54\% of those who had positive margins and may have done so in a further $32.4 \%$ of cases with positive margins that did not have CS taken. Several other studies have shown the use of CS to decrease re-excision rates. Jacobson et al18 in a small review of 125 cases undergoing WLE and simultaneous CS excision found $49 \%$ had a positive resection margin but clear CS thus negating the need for a second operation. Keskek et al1 ${ }^{[9]}$ took all $4 \mathrm{CS}$ after $301 \mathrm{WLE}$ and in $50 \%$ of those with involved margins the CS were clear, thus a second operation was not required. A retrospective analysis of 126 WLE and CS by Cao et al ${ }^{[20]}$ showed that CS rendered the overall excision complete in $59 \%$ of cases with positive margins. Huston et al ${ }^{[21]}$ compared outcomes between 49 patients who underwent WLE only with 77 WLE with selective CS and 45 WLE with all four CS taken. The re-operation rate if no CS were taken was $38.7 \%, 32.5 \%$ if selective CS taken and reduced to $17.7 \%$ if all four CS were taken.

In patients undergoing re-excision following positive margins or positive CS the percentage with residual disease in our study was $27 \%$ which is slightly lower than the rates of between $35-57.8 \%$ reported by other studies ${ }^{[14,22-24]}$. However $8 \%$ of our patients with positive margins/CS did not have further surgery so it is unknown how many of these would have had residual disease.

The positive CS rate in our study was $26.9 \%$. Other studies report positive CS rates of $17.4-50.2 \%{ }^{[14,18-20,23-25]}$. CS positivity has been shown to be associated with younger age, tumour type, size and grade, extensive intraductal component, multifocality and axillary node status ${ }^{[14,19,20,23]}$. We therefore suggest that if a surgeon is going to take selective CS, they should have a lower threshold for taking them in patients with these characteristics.

We conclude from this study that Surgeons are more likely to overestimate margin involvement during breast conserving surgery and often do not identify the correct margin involved. However, the routine use of four cavity shaves would result in excess tissue removal in a higher number of patients than the number that would be aided by performing cavity shaves. We suggest that routine cavity shaves are not beneficial for all patients; instead surgeons should consider taking a more generous excision specimen in those at higher risk of involved margins.

\section{Conflict of competing interests}

There are no organizations or communities with conflict of interest or coveting interests related to the study. The co-authors declare that they have no competing interests.

\section{References}

[1] Jeevan R, Browne J, van der Meulen J, et al. First annual report of the National Mastectomy and Breast Reconstruction Audit 2008. NHS Information Centre, 2008.

[2] Poggi MM, Danforth DN, Sciuto LC, et al. Eighteen year results in the treatment of early breast carcinoma with mastectomy versus breast conservation therapy. The National Cancer Institute Randomized Trial. Cancer. 2003; 98(4): 697-702. PMid:12910512 http://dx.doi.org/10.1002/cncr.11580

[3] Early Breast Cancer Trialists' Collaborative Group. Effects of Radiotherapy and surgery in early breast cancer. An overview of the randomised trials. NEJM. 1995; 333(22): 1444-1455. PMid:7477144 http://dx.doi.org/10.1056/NEJM199511303332202 
[4] Morris AD, Morris RD, Wilson JF, et al. Breast conserving therapy versus mastectomy in early breast cancer: a metanalysis of 10 year survival. Cancer J Sci Am. 1997; 3(1): 6-12. PMid:9072310

[5] Simone NL, Dan T, Shih J, et al. Twenty five year results of the national cancer institute randomised breast conservation trial. Breast Cancer Research \& Treatment. 2012; 132(1): 197-203. PMid:22113254 http://dx.doi.org/10.1007/s10549-011-1867-6

[6] Litiere S, Werutsky G, Fentiman IS, et al. Breast conserving therapy versus mastectomy for stage I-II breast cancer: 20 year follow up of the EORTC 10801 phase 3 randomised trial. Lancet Oncol. 2012;13(4): 412-9. http://dx.doi.org/10.1016/S1470-2045(12)70042-6

[7] Fisher B, Anderson S, Bryant J, et al. Twenty -year follow-up of a randomized trial comparing total mastectomy, lumpectomy, and lumpectomy plus irradiation for the treatment of invasive breast cancer. NEJM. 2002; 347(16):1233-41. PMid:12393820 http://dx.doi.org/10.1056/NEJMoa022152

[8] Houssami N, Macaskill P, Marinoich ML, et al. Meta-analysis of the impact of surgical margins on local recurrence in women with early-stage invasive breast cancer treated with breast-conserving surgery. Eur J Cancer. 2010; 46(18): 3219-32. PMid:20817513 http://dx.doi.org/10.1016/j.ejca.2010.07.043

[9] Freedman G, Fowble B, Hanlon A, et al. Patients with early stage invasive cancer with close or positive margins treated with conservative surgery and radiation have an increased risk of breast recurrence that is delayed by adjuvant systemic therapy. Int $\mathrm{J}$ Radiat Oncol Biol Phys. 1999; 44(5):1005-15. http://dx.doi.org/10.1016/S0360-3016(99)00112-1

[10] Beasan-Ciani I, Greenall MJ. The importance of margin status after breast-conserving surgery and radiotherapy in node positive patients: a follow-up of 10-15 years. International seminars in Surgical Oncology. 2008; 5: 13. PMid:18498621 http://dx.doi.org/10.1186/1477-7800-5-13

[11] Clarke M, Collins R, Darby S, et al. Effects of Radiotherapy and of differences in extent of surgery for early breast cancer on local recurrence and 15 year survival: an overview of the randomised trials. Lancet. 2005: 366: 2087-106. PMid:16360786

[12] Mansfield CM, Komarnicky LT, Schwartz GF, et al. Ten-year results in 1070 patients with stages I and II breast cancer treated by conservative surgery and radiation therapy. Cancer. 1995: 75(9): 2328-36 http://dx.doi.org/10.1002/1097-0142(19950501)75:9<2328::AID-CNCR2820750923>3.0.CO;2-L

[13] Aziz D, Rawlinson E, Narod SA, et al. The role of reexcision for positive margins in optimizing local disease control after breast-conserving surgery for cancer. Breast J. 2006: 12(4): 331-7. PMid:16848842 http://dx.doi.org/10.1111/j.1075-122X.2006.00271.x

[14] Malik HZ, George WD, Mallon EA, et al. Margin assessment by cavity shaving after breast-conserving surgery: analysis and follow-up of 543 patients. Eur J Surg Oncol.1999: 25(5): 464-9. PMid:10527593 http://dx.doi.org/10.1053/ejso.1999.0680

[15] Jeevan R, Cromwell DA, Trivella M, et al. Reoperation rates after breast conserving surgery for breast cancer among women in England: retrospective study of hospital episode statistics. BMJ. 2012; 345: e4505.

PMid:22791786 http://dx.doi.org/10.1136/bmj.e4505

[16] Jacobs L. Positive margins:the challenge continues for breast surgeons. Ann Surg Oncol. 2008: 15: 1271-2. PMid:18320287 http://dx.doi.org/10.1245/s10434-007-9766-0

[17] Menes TS, Tartter PI, Bleiweiss I, et al. The consequence of multiple re-excisions to obtain clear lumpectomy margins in breast cancer patients. Ann Surg Oncol. 2005; 12(11): 881-5. PMid:16195834 http://dx.doi.org/10.1245/ASO.2005.03.021

[18] Jacobson AF, Asad J, Boolbol SK, et al. Do additional shaved margins at the time of lumpectomy eliminate the need for re-excision? Am J Surg. 2008; 196(4): 556-8. PMid:18809063 http://dx.doi.org/10.1016/j.amjsurg.2008.06.007

[19] Keskek M, Kothari M, Ardehali B, et al. Factors predisposing to cavity margin positivity following conservation surgery for breast cancer. EJSO 2004; 30:1058-1064. PMid:15522551 http://dx.doi.org/10.1016/j.ejso.2004.07.019

[20] Cao D, Lin C, Woo SH, et al. Separate cavity margin sampling at the time of initial breast lumpectomy significantly reduce the need for re-excisions. AM J Surg Pathol. 2005: 29(2): 1625-1632. PMid:16327435 http://dx.doi.org/10.1097/01.pas.0000180448.08203.70

[21] Huston TL, Pigalarga R, Osborne MP, et al. The influence of additional surgical margins on the total specimen volume excised and the re-operative rate after breast-conserving surgery. Am J Surg. 2006: 192(4): 509-12. PMid:16978962 http://dx.doi.org/10.1016/j.amjsurg.2006.06.021

[22] Kouzminova NB, Aggarwal S, Aggarwal A, et al. Impact of initial surgical margins and residual cancer upon re-excision on outcome of patients with localized breast cancer. Am J Surg. 2009;198(6): 771-80. PMid:19969128 http://dx.doi.org/10.1016/j.amjsurg.2009.05.027

[23] Barthelmes L, Al Awa A, Crawford DJ. Effect of cavity margin shavings to ensure completeness of excision on local recurrence rates following breast conserving surgery. EJSO. 2003; 29: 644-648. http://dx.doi.org/10.1016/S0748-7983(03)00122-7

[24] Macmillan RD, Purushotham AD, Mallon E, et al. Tumour bed positivity predicts outcome after breast conserving surgery. BJS 1998: 85: 1559-1562. 
[25] Beck NE, Bradburn MJ, Vincenti AC, et al. Detection of residual disease following breast conserving surgery. BJS. 1998: 85: 1273-1276. PMid:9752875 http://dx.doi.org/10.1046/j.1365-2168.1998.00876.x 